\title{
Reduction Charge Smaller than the Deposited One in Cathodic Stripping Voltammograms of AgCl
}

\author{
Peng Tang1, Koichi Jeremiah Aoki², Jingyuan Chen ${ }^{1 *}$ (i) \\ ${ }^{1}$ Department of Applied Physics, University of Fukui, Fukui, Japan \\ ${ }^{2}$ Electrochemistry Museum, Fukui, Japan \\ Email: `jchen@u-fukui.ac.jp
}

How to cite this paper: Tang, P., Aoki, K.J. and Chen, J.Y. (2019) Reduction Charge Smaller than the Deposited One in Cathodic Stripping Voltammograms of AgCl. American Journal of Analytical Chemistry, 10, 286-295.

https://doi.org/10.4236/ajac.2019.108021

Received: July 15, 2019

Accepted: August 11, 2019

Published: August 14, 2019

Copyright $\odot 2019$ by author(s) and Scientific Research Publishing Inc. This work is licensed under the Creative Commons Attribution International License (CC BY 4.0).

http://creativecommons.org/licenses/by/4.0/

\begin{abstract}
A silver electrode was anodized in lowly concentrated potassium chloride solution almost under the steady state to generate a deposit of silver chloride on the electrode, and the deposit was cathodically stripped by linear potential scan to evaluate the reduction charge. Then the oxidation charge was larger than the reduction one. Since the equality was valid for long term chronocoulometry at the double potential step, the inequality is not due to any irreversibility of electrode reactions, but can be attributed to the process of the cathodic potential scan. A reason for the inequality is the negative charge of the capacitance involved in the electrode reaction, which has been observed in simple, dissolved redox species like a ferrocenyl derivative. The negative capacitive currents are conspicuous for high concentrations of redox species on the electrode because they result from the orientation of the dipoles of the redox species coupled with counterion, of which direction is opposite to that of the solvent dipoles. If a silver chloride film was thin enough to be regarded as a monolayer, we found that half of the cathodic stripping charge should be lost by the negative capacitance.
\end{abstract}

\section{Keywords}

Silver Electrode, Double Layer Capacitance, Stripping Voltammetry, Chronocoulometry, Time-Dependent Charge

\section{Introduction}

Cathodic stripping voltammetry has been used for quantitative determination of ions which form sparingly soluble salts with anodically generated species. The insoluble salts are stripped cathodically to evaluate the charge which may be 
proportional to concentrations of the ions to be determined [1] [2]. This technique has been applied to determine arsenic in sea water [3], traces of telluriu [4], aluminum, chromium and titanium [5], nickel generated in sonoelectrochemistry [6], tryptophan and histidine [7], trace antimony [8], cerium [9], selenium in freshwaters [10], iron in seawater [11] [12], titanium in seawater [13], manganese [14].

A key of stripping voltammetry lies in the equivalence between the stripped charge and the accumulated one which is proportional to concentrations of anionic analyte. The equivalence may not be ensured when 1) stability constants of the sparingly soluble salts are not large enough to be influenced by foreign species, 2) all the deposits are not electrochemically stripped owing to dispersion in a form of small particles to solution, and 3) the stripped charge includes capacitive charge. The first belongs to a chemical subject, and can be solved by selecting kinds of sparingly soluble salts. The second is a physical subject on uniform dissolution associated with the electric percolation [15]. If a part of the deposit near the electrode is dissolved more exceedingly than the other part near the solution, the latter loses an electric path to the electrode. As a result, it cannot be reduced electrochemically any more, and maybe dispersed to the solution in the form of salt particles, as illustrated in Figure 1. The loss of the electric path has been found in the reduction of electrically conducting polyaniline films [16] [17] [18] as well as polyaniline-coated latex particles [19].

The third item involves techniques of subtracting capacitive currents. There are two sources of double layer capacitors, one being due to orientation of solvent dipoles [20] [21] in Stern's (inner) layer [22], the other being to orientation of redox dipoles [23] [24] [25]. Since the latter is oriented in the opposite direction to the former, it shows negative values of the capacitance at high concentrations of redox species on the electrode. The deposit of insoluble species takes much higher concentration than the concentrations of diffusing redox species. Consequently, the effect of negative capacitance should contribute largely to the determination of the stripped charge.

This paper aims at evaluating a relationship between the accumulated charge and the negatively capacitive charge in cathodic stripping voltammetry of chloride ion in solution at a silver electrode. Silver chloride is deposited on the Ag electrode by a constant anodic voltage for a long time to evaluate the deposition charge. The charge does not include a capacitive component because of steady-state electrolysis. The cathodic charge is evaluated from integration of cathodically

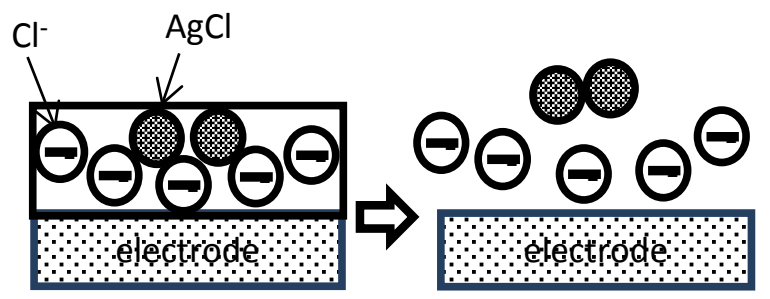

Figure 1. Reduction of salt molecules on the electrode to make them electrical insulator, which interrupt the reduction of upper salt molecules. 
scanned voltammograms, which is composed of the reduction charge and the negative capacitive charge. The capacitive charge is caused by the potential scan. Then the observed charge is different by the amount of capacitive charge. The negative capacitance at thick film will be shown to be cancelled with the double layer capacitive charge for dendrite formation.

\section{Experiments}

All the chemicals were of analytical grade purchased from Nilaco (Tokyo), and were used as received. Water employed was distilled and then ion-exchanged. The working electrode was a silver wire $0.5 \mathrm{~mm}$ in diameter with $99.99 \%$ purity purchased by Nilaco (Tokyo). The electrode surface was polished with sand paper and then with $0.3 \mu \mathrm{m}$ aluminum powder. The wire was inserted into solution by ca. $10 \mathrm{~mm}$ in depth with an optical stage. The accurate length of the immersion was determined from photographs. The usage of the wire instead of an inlaid disk prevented us from floating capacitance caused at the insulator|electrode boundary.

The reference electrodes were the $\mathrm{Ag} \mid \mathrm{AgCl}$ electrode in saturated $\mathrm{KCl}$ solution, the $\mathrm{Ag} \mid \mathrm{Ag}_{x} \mathrm{O}$ electrode which was formed by immersing a silver wire in concentrated $\mathrm{HNO}_{3}$ for a few minutes, and the $\mathrm{Ag} \mid \mathrm{AgCl}$ electrode directly inserted in a test solution. Although the second one and the last showed unstable equilibrium potentials for a long time measurement, they were helpful for avoiding leakage of chloride ion from the $\mathrm{Ag} \mid \mathrm{AgCl}$ electrode. The unstable potential was corrected by use of $\mathrm{Ag} \mid \mathrm{AgCl}$ (sat. $\mathrm{KCl}$ ). All the potentials here were represented in terms of the potential at $\mathrm{Ag} \mid \mathrm{AgCl}$ (sat. $\mathrm{KCl}$ ). The counter electrode was a platinum coil. A potentiostat was CompactStat (Ivium, Netherlands).

All the solutions were deaerated with nitrogen gas for 20 min before each voltammetric run. The solution of the $\mathrm{pH}$ was adjusted to 3.0 by addition of $\mathrm{HNO}_{3}$. We have examined effects of $\mathrm{pH}$ of the solution for fear of formation of $\mathrm{Ag}(\mathrm{OH})$, but found no dependence on $\mathrm{pH}$ so far as $\mathrm{pH}$ less than 5 .

\section{Results and Discussion}

Voltammograms in $0.1 \mathrm{M} \mathrm{KNO}_{3}$ at the $\mathrm{Ag}$ working electrode and the $\mathrm{Ag} \mid \mathrm{AgCl}$ reference electrode showed the rising oxidation current and the peaked reduction wave, as shown in Figure 2(a). When the cell was left for an hour in the $\mathrm{N}_{2}$ atmosphere, a new oxidation and a reduction wave appeared at ca. $0.3 \mathrm{~V}$ and ca $0.2 \mathrm{~V}$, respectively (Figure $2(\mathrm{~b})$ ). These waves are predicted to be caused by formation of $\mathrm{AgCl}$ with chloride ion leaking from the $\mathrm{Ag} \mid \mathrm{AgCl}$ reference electrode. Since these waves were found by adding a small drop of $\mathrm{KCl}$ solution into the $0.1 \mathrm{M} \mathrm{KNO}_{3}$ solution, they can be obviously attributed to be the reaction $\mathrm{AgCl}+\mathrm{e}^{-}=\mathrm{Ag}+\mathrm{Cl}^{-}$. The behavior was also found by use of the saturated calomel electrode. Leakage of chloride ion has been significant in deionized latex suspensions [26]. Few attentions have been paid to the leakage although kinetic 


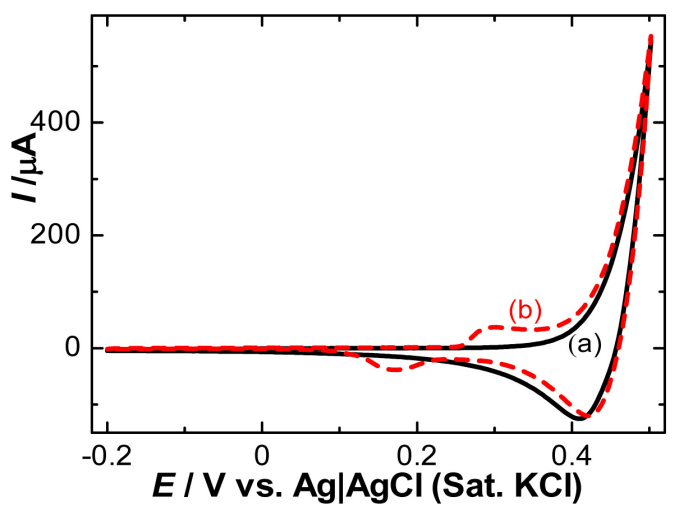

Figure 2. Voltammograms in $0.1 \mathrm{M} \mathrm{KNO}_{3}$ at the Ag electrode observed (a) immediately after and (b) an hour after inserting the $\mathrm{Ag} \mid \mathrm{AgCl}$ (sat. $\mathrm{KCl}$ ) into the solution.

work on silver halides has a long term history for $\mathrm{AgCl}$ [27], $\mathrm{AgBr}$ [28] and $\mathrm{AgI}$ [29] [30].

A test solution includes low concentrations of $\mathrm{Cl}^{-}$, which can work as a solution of a reference electrode just by inserting the AgCl-coated silver wire in the solution. This reference electrode exhibited such a stable equilibrium potential that cyclic voltammetric peak potentials of deposition and dissolution of $\mathrm{AgCl}$ did not change for a few hours under the deaerated $\mathrm{AgNO}_{3}$ solution. Unfortunately, these peak potentials varied slightly with bulk test solutions. We have confirmed that the peak potentials obeyed the Nernst equation for various concentrations, from which the shift of the potential by the AgCl-coated silver wire was estimated. All the potentials described here are the thus corrected values vs. $\mathrm{Ag} \mid \mathrm{AgCl}$ (sat. $\mathrm{KCl}$ ).

The anodic peak currents were proportional to not only $v^{1 / 2}(v$. potential scan rate), i.e. linear to $v^{1 / 2}$ with the intercept of zero current, but also the concentration of $\mathrm{Cl}^{-}$. Therefore the anodic current should be controlled by diffusion of $\mathrm{Cl}^{-}$. We evaluated the diffusion coefficient of $\mathrm{Cl}^{-}$to be $1.48 \times 10^{-5} \mathrm{~cm}^{2} \cdot \mathrm{s}^{-1}$ from these proportionality constants.

Potential $0.28 \mathrm{~V}$ was applied to the silver electrode in the deaerated $0.2 \mathrm{mM}$ $\mathrm{KCl}+0.1 \mathrm{M} \mathrm{KNO}_{3}$ solution to generate $\mathrm{AgCl}$ for a given period, and was anodically scanned, as shown in the right ordinate of Figure 3. The responding cathodic current was almost constant after $1 \mathrm{~s}$ (in the left ordinate of Figure 3) without noticeable charging current. The integration of the current yielded the oxidation charge, $q_{o}$. In contrast, the reduction current increased rapidly with the linear potential scan, showed a peak, decreased drastically, and increased slightly with the time. The last increase may be caused by double layer (DL) charging current, because the linear increase in the capacitance can be explained by the electrically percolated silver and because the large current $(-40 \mu \mathrm{A})$ can be interpreted as the DL capacitance of the percolated silver $\left(\mathrm{ca} .1 \mathrm{mF} \cdot \mathrm{cm}^{-2}\right)$. We eliminated the capacitive contribution indicated as the dashed line ( (a) in Figure 3$)$ from the reduction current, and evaluated the reduction charge, $q_{r}$.

Figure 4 shows the variations of $q_{o}$ and $-q_{r}$, against the oxidation time, $t_{o}$ at 


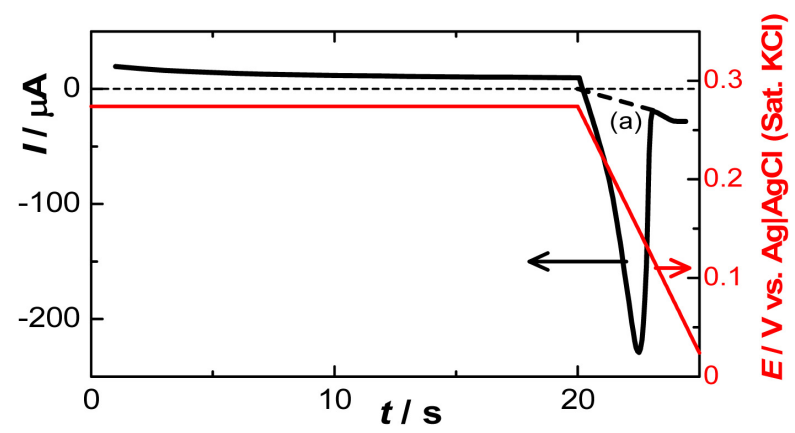

Figure 3. Current-time curve in the left axis in $0.2 \mathrm{mM} \mathrm{KCl}+0.1 \mathrm{M} \mathrm{KNO}_{3}$ solution, and variation of the voltage with the in the right axis at $v=0.05 \mathrm{~V} \cdot \mathrm{s}^{-1}$. Line (a) is a background current.

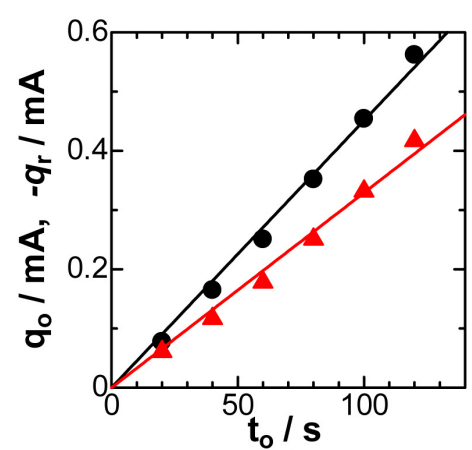

(a)

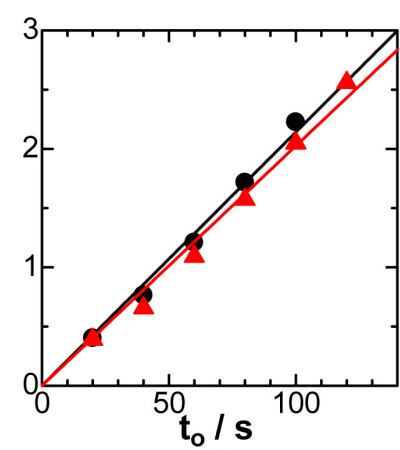

(b)

Figure 4. Variations of (circles) $q_{o}$ and (triangles) $q_{r}$ with the oxidation time, $t_{o}$, of the cathodic stripping in the solution (a) $0.4 \mathrm{mM} \mathrm{KCl}$ and (b) $2 \mathrm{mM} \mathrm{KCl}$ including $1 \mathrm{M}$ $\mathrm{KNO}_{3}+1 \mathrm{mM} \mathrm{HNO}$ at $v=0.05 \mathrm{~V} \cdot \mathrm{s}^{-1}$ when the oxidation potentials were (a) 0.266 and $0.225 \mathrm{~V}$ vs. $\mathrm{Ag} \mid \mathrm{AgCl}$ (sat. $\mathrm{KCl}$ ).

given constant potentials. The proportionality of $q_{o}$ to $t_{o}$ indicates some kinetic control of the oxidation rather than diffusion, and demonstrates to include no double layer charge, otherwise an intercept might appear [31]. Although $q_{o}$ should be compensated with $q_{r}$, according to the conventional concept of the charge balance on the electrode, observed values of $\left|q_{r}\right|$ were always smaller than $q_{o}$. The loss of the charge can be attributed to chemical complications such as dissolution of deposit $\mathrm{AgCl}$, and items 2) and 3) described in Introduction. Firstly, we examine a possibility of chemical complications. If silver hydroxide or silver oxide is deposited electrochemically on the electrode, $q_{r}$ should be larger than the charge predicted from concentrations of $\mathrm{Cl}^{-}$. Acidic solutions ( $\mathrm{pH}$ from 2 to 6) had no effect on the ratio, $\left|q_{t}\right| / q_{o}$, and hence silver hydroxide does not participate in the inequality $\left(\left|q_{r}\right|<q_{o}\right)$. Silver ion diffusing in the bulk solution takes ca. 4 $\mu \mathrm{M}$ in $0.4 \mathrm{mM} \mathrm{KCl}$ solution. It cannot contribute to $q_{r}$ There seems no possible chemical species of blocking the reduction.

In order to search unrecognized possibility of chemical contribution to the inequality, we carried out long-term double potential chronocoulometry. Application of a constant voltage generated the $\mathrm{AgCl}$ deposit, which was reduced by a constant potential. Figure 5 shows the dependence of the ratio of the oxidation 


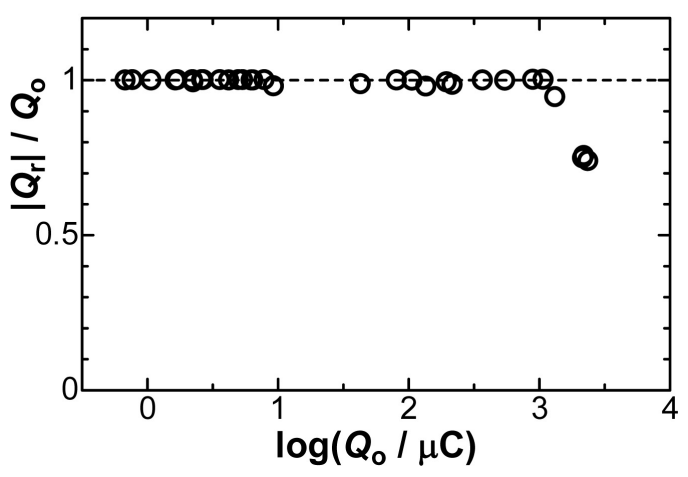

Figure 5. Variation of the ratio of the reduction charge at $0.005 \mathrm{~V}$ vs. $\mathrm{Ag} \mid \mathrm{AgCl}$ (sat. $\mathrm{KCl}$ ) to that of the oxidation one at $0.244 \mathrm{~V}$ by the double potential step chronoamperometry in the solution of $0.2 \mathrm{mM} \mathrm{KCl}+0.1 \mathrm{M} \mathrm{KNO}_{3}$. Oxidation times ranged from $30 \mathrm{~s}$ to $270 \mathrm{~s}$.

charge to the reduction one, $\left|Q_{t}\right| Q_{o}$, on $Q_{o}$. The ratios for $-0.2<\log \left(Q_{o} / \mu \mathrm{C}\right)<$ 3.0 were unity, indicating the charges should be balanced. The difference in the variations between in Figure 4 and in Figure 5 should lie in the electrochemical techniques, i.e. the cathodic potential scan in Figure 4, which necessarily brings about the capacitive current. Therefore, the unbalance ought to be caused by the negative capacitance of redox reactions [23] [24] [25]. The decrease in the ratio for $\log \left(Q_{d} / \mu \mathrm{C}\right)>3.0$ may be caused by a loss of electric path for the reduction of $\mathrm{AgCl}$ by the percolation, as illustrated in Figure 1. The $\mathrm{AgCl}$ deposits for $\log \left(Q_{d} / \mu \mathrm{C}\right)=0$ and 3 have the densities of $6.5 \times 10^{-11}$ and $6.5 \times 10^{-8} \mathrm{~mol} \cdot \mathrm{cm}^{-2}$, respectively, which correspond to 4 and $4000 \mathrm{AgCl}$ molecules per $\mathrm{nm}^{2}$. Therefore, the point on the left in Figure 5 represents a monolayer, while that on the right does a thick film with more than 400 layers.

The negative capacitance can be represented by $q_{o}-\left|q_{r}\right|$. If it is caused only the redox reaction, values of $q_{o}-\left|q_{t}\right|$ should be proportional to $q_{o}$ or $\left(q_{o}-\left|q_{t}\right|\right) / q_{o}$ be a constant. Figure 6 shows variation of $\left(q_{o}-\left|q_{T}\right|\right) / q_{o}$ with $\log q_{o}$, obtained by change in concentrations of $\mathrm{KCl}$ and oxidation potentials. The prediction fails, the ratio decreasing with an increase in $q_{o}$, although the proportionality of $q_{o}$ and $q_{r}$ with $t_{o}$ was retained as in Figure 4(b). In anodic stripping voltammetry, the scanned potential for the deposited silver can oxidize the silver atoms at any location so far as they have electric connection to the electrode. In contrast, the reduction of an $\mathrm{AgCl}$ molecule in cathodic stripping voltammetry requires a contact with the electrically percolated silver atoms. Thus, it begins only at the substrate silver electrode, and then the reduction is propagated toward the film|solution interface. When percolated silver atoms grow in dendrite form, the surface of the dendrite works as an electrode of the cathodic stripping. As a result, the area of the silver|solution becomes much larger than the projected area of the electrode, as illustrated in the inset of Figure 6. Then the DL capacitance by the solvent dipoles should increase to compensate the negative capacitance, yielding the decrease in $\left(q_{o}-\left|q_{r}\right|\right) / q_{o}$ with the increase in the film thickness.

We estimate the dependence of the DL capacitance by the solvent dipoles at the dendrite|solution interface on $q_{o}$. The silver atoms reduced from $\mathrm{AgCl}$ are 


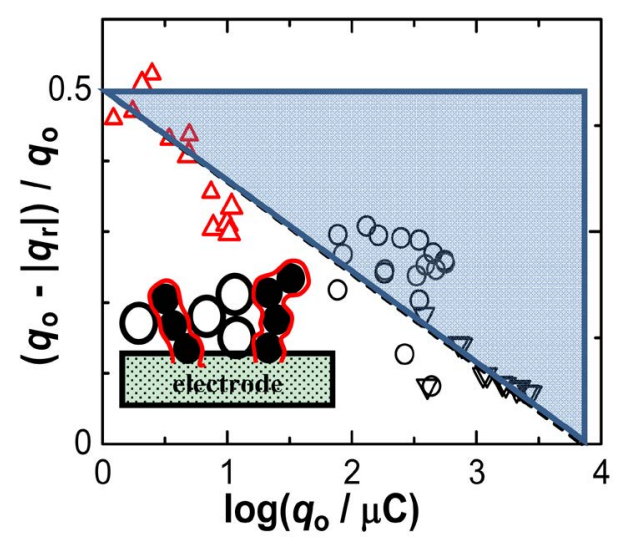

Figure 6. Dependence of the normalized negatively capacitive charge on the logarithms of the oxidation charge obtained for various values of oxidation potentials and in solutions of (triangles) $0.1 \mathrm{M} \mathrm{KNO}_{3}+0.4 \mathrm{mM} \mathrm{KCl}+1 \mathrm{mM} \mathrm{HNO}_{3}$, (circles) $0.1 \mathrm{M} \mathrm{KNO}_{3}+0.4$ $\mathrm{mM} \mathrm{KCl}$ and (inverse triangles) $0.1 \mathrm{M} \mathrm{KNO}_{3}+2 \mathrm{mM} \mathrm{KCl}+1 \mathrm{mM} \mathrm{HNO}_{3}$. The inset illustrates silver dendrite (filled circles) around which the DL capacitor is formed.

necessarily adjacent to silver atoms, silver chloride molecules or water molecules, the last of which can generate the DL capacitance, $C$. Let the amount of the silver atoms on the electrode be $w$, which are electrically percolated to the electrode. $C$ is a function of $w, C(w)$. When a small amount of silver atoms, $\Delta w$, is generated by the electrode reaction, the capacitance is not formed only in the added amount, but should be formed over the whole silver atoms because of the electric percolation. It is all the percolated silver atoms that can compensate the increment by the reduction. Thus, the increment of the capacitance is proportional to $(\Delta w) / w$ rather than $\Delta w$. As a result we have

$$
C(w+\Delta w)-C(w)=k(\Delta w) / w
$$

where $k$ is a proportional constant. The Taylor expansion, $C(w+\Delta w)=C+$ $(\mathrm{d} C / \mathrm{d} w) \Delta w+\ldots$, leads Equation (1) to $\mathrm{d} C / \mathrm{d} w=k / w$. The integration on the condition of $C=0$ at $w=w_{0}$ yields

$$
C=k \ln \left(w / w_{0}\right)
$$

Since $w$ is equivalent to $q_{r}$, it should be proportional to $q_{o}$. Therefore, the DL capacitance has the linear relation with $\log q_{0}$. This contribution is equivalent to the inverse triangle in Figure 6. Consequently, the observed reduction charge varies linearly with $\log q_{o}$.

From Figure 6, this value is close to the experimental one for $\log \left(q_{o} / \mu \mathrm{C}\right) \rightarrow 0$, corresponding to a monolayer. A half the faradaic charge is consumed by the negative capacitance. When cathodic stripping is applied to quantitative determination of anions in solution, a calibration curve is predicted to be not linear but to exhibit low deviation from the calibration line at lower concentrations.

\section{Conclusions}

The negative capacitance is involved in the cathodic stripping voltammograms so that the reduction charge is smaller than the deposited charge. When the amount 
of the deposit is close to a monolayer, the reduction charge is half of the oxidation one because of the negative capacitive charge by the redox reaction. In contrast, deposits with as high as $10^{-7} \mathrm{~mol} \cdot \mathrm{cm}^{-2}$ provide apparently the reduction charge equivalent to the oxidation one. However, the similarity of the charges is not due to the reversible redox reaction, but is ascribed to the compensation of the negatively capacitive charge with the DL charge by solvent dipoles.

The ratio $\mid q_{t} / q_{o}$ varies with values of $q_{o}$, and hence a calibration curve for quantitative determination of anions does not take a line. It is dangerous to extrapolate the calibration line to zero concentration. Evaluated concentration may be overestimated.

\section{Conflicts of Interest}

All authors report no conflicts of interest relevant to this article.

\section{References}

[1] Achterberg, E.P., Barriada, J.L. and Braungardt, C.B. (2005) Encyclopedia of Analytical Science. 2nd Edition, Elsevier, Oxford, 203-211.

[2] Wang, J. (1985) Stripping Analysis: Principles, Instrumentation, and Applications. VCH Publishers, Inc., Deerfield Beach, FL.

[3] Zima, J. and van denBerg, C.M.G. (1994) Determination of Arsenic in Sea Water by Cathodic Stripping Voltammetry in the Presence of Pyrrolidine Dithiocarbamate. Analytica Chimica Acta, 289, 291-298. https://doi.org/10.1016/0003-2670(94)90004-T https://www.sciencedirect.com/science/article/pii/000326709490004T

[4] Ishiyama, T. and Tanala, T. (1988) Cathodic Stripping Voltammetry of Tellurium(IV) at a Rotating Silver Disk Electrode. Analytical Sciences, 14, 677-680. https://doi.org/10.2116/analsci.14.677

[5] van den Berg, C.M.G., Boussemart, M., Yokoi, K., Prartono, T. and Campos, M.L.A.M. (1994) Speciation of Aluminum, Chromium and Titanium in the NW Mediterranean. Marine Chemistry, 45, 267-282. https://doi.org/10.1016/0304-4203(94)90074-4

[6] Davis, J., Vaughan, D.H., Stirling, D., Nei, L. and Compton, R.G. (2002) Cathodic Stripping Voltammetry of Nickel: Sonoelectrochemical Exploitation of the $\mathrm{Ni}(\mathrm{III}) / \mathrm{Ni}(\mathrm{II})$ Couple. Talanta, 57, 1045-1051. https://doi.org/10.1016/S0039-9140(02)00148-0

[7] Ensafi, A. A. and Hajian, R. (2006) Determination of Tryptophan and Histidine by Adsorptive Cathodic Stripping Voltammetry Using H-point Standard Addition Method. Analytica Chimica Acta, 80, 236-243. https://doi.org/10.1016/j.aca.2006.07.076

[8] Su, J., Zhong, S., Li, X. and Zou, H. (2014) Determination of Trace Antimony by Square-Wave Adsorptive Cathodic Stripping Voltammetry at an ex Situ Prepared Bismuth Film Electrode. Journal of the Electrochemical Society, 161, H512-H516. https://doi.org/10.1149/2.0521409jes

[9] Dolezal, J., Hrabánková, E. and Maěín, V. (1971) Cathodic Stripping Voltammetry of Cerium. Analytical Letters, 4, 887-892. https://doi.org/10.1080/00032717108066076 https://www.tandfonline.com/doi/abs/10.1080/00032717108066076

[10] Mattsson, G., Nyholm, L., Olin, A. and Ornemark, U. (1995) Ornemark, Determination of Selenium in Freshwaters by Cathodic Stripping Voltammetry after UV Ir- 
radiation. Talanta, 42, 817-825. https://doi.org/10.1016/0039-9140(95)01494-V

[11] van den Berg, C.M.G. (2006) Chemical Speciation of Iron in Seawater by Cathodic Stripping Voltammetry with Dihydroxynaphthalene. Analytical Chemistry, 78, 156-163. https://doi.org/10.1021/ac051441+

[12] Laglera, L.M., Santos-Echeandía, J., Caprara, S. and Monticelli, D. (2013) Quantification of Iron in Seawater at the Low Picomolar Range Based on Optimization of Bromate/Ammonia/Dihydroxynaphtalene System by Catalytic Adsorptive Cathodic Stripping Voltammetry. Analytical Chemistry, 85, 2486-2492. https://doi.org/10.1021/ac303621q

[13] Croot, P.L. (2011) Rapid Determination of Picomolar Titanium in Seawater with Catalytic Cathodic Stripping Voltammetry. Analytical Chemistry, 83, 6395-6400. https://doi.org/10.1021/ac201450k

[14] Kang, W., Pei, X., Bange, A., Haynes, E.N., Heineman, W.R. and Papautsky, I. (2014) Copper-Based Electrochemical Sensor with Palladium Electrode for Cathodic Stripping Voltammetry of Manganese. Analytical Chemistry, 86, 12070-12077. https://doi.org/10.1021/ac502882s

[15] Stauffer, D. and Aharony, A. (1992) Introduction to Percolation Theory. 2nd Edition, Taylor \& Francis, London.

[16] Cao, J. and Aoki, K. (1996) Percolation Threshold Potentials at Quasi-Static Electrochemical Switching of Polyaniline Films. Electrochimica Acta, 41, 1787-1792. https://doi.org/10.1016/0013-4686(95)00496-3

[17] Aoki, K., Edo, T. and Cao, J. (1997) Potential-Step Response of Absorption at Conducting-to-Insulating Conversion of Polyaniline Films for Demonstrating the Slow Relaxation. Electrochimica Acta, 43, 285-289. https://doi.org/10.1016/S0013-4686(97)89695-8

[18] Aoki, K., Teragishi, Y. and Tokieda, M. (1999) Light Scattering of Polyaniline Films Responding to Electrochemical Switching. Journal of Electroanalytical Chemistry, 460, 254-257. https://doi.org/10.1016/S0022-0728(98)00356-8

[19] Chen, H., Chen, J., Aoki, K. and Nishiumi, T. (2008) Electrochemically Instantaneous Reduction of Conducting Polyaniline-Coated Latex Particles Dispersed in Acidic Solution. Electrochimica Acta, 53, 7100-7106. https://doi.org/10.1016/j.electacta.2008.04.084

[20] Hou, Y., Aoki, K.J., Chen, J. and Nishiumi, T. (2013) Invariance of Double Layer Capacitance to Polarized Potential in Halide Solutions. Universal Journal of Chemistry, 1, 162-169.

[21] Hou, Y., Aoki, K.J., Chen, J. and Nishiumi, T. (2014) Solvent Variables Controlling Electric Double Layer Capacitance at Metal-Solution Interface. Journal of Physical Chemistry C, 118, 10153-10158. https://doi.org/10.1021/jp5018289

[22] Bard, A.J. and Faulkner, L.R. (2001) Electrochemical Methods: Fundamentals and Applications. 2nd Edition, John Wiley\& Sons, New York.

[23] Aoki, K.J., Chen, J., Zeng, X. and Wang, Z. (2017) Decrease in Double Layer Capacitance by Faradaic Current. RSC Advances, 7, 22501-22501. https://doi.org/10.1039/C7RA01770G

[24] Aoki, K.J. and Chen, J. (2018) Effects of the Dipolar Double Layer on Elemental Electrode Processes at Micro- and Macro-Interfaces. Faraday Discussions, 210, 219-234. https://doi.org/10.1039/C7FD00212B

[25] Aoki, K.J., Chen, J. and Tang, P. (2018) Capacitive Currents Flowing in the Direction Opposite to Redox Currents. Journal of Physical Chemistry C, 122, 16727-16732. 
https://doi.org/10.1021/acs.jpcc.8b03335

[26] Aoki, K., Zhao, X., Chen, J. and Nishiumi, T. (2013) Voltammetry in Low Concentration of Electrolyte Supported by Ionic Latex Suspensions. Journal of Electroanalytical Chemistry, 797, 5-9. https://doi.org/10.1016/j.jelechem.2013.03.008

[27] Briggs, G.W. and Thirsk, H.R. (1952) A Study of the Behaviour of Polarized Electrodes. Part 3. The Behaviour of the Silver/Silver Chloride System during Electrolytic Reduction. Transactions of the Faraday Society, 48, 1171-1178. https://doi.org/10.1039/TF9524801171

[28] Birss, V.I. and Wright, G.A. (1982) The Kinetics of Silver Bromide Film Formation on the Silver Anode. Electrochimica Acta, 27, 1429-1437.

https://doi.org/10.1016/0013-4686(82)80034-0

[29] Birss, V.I. and Wright, G.A. (1982) The Kinetics of Silver Iodide Film Formation on the Silver Anode. Electrochimica Acta, 27, 1439-1443.

https://doi.org/10.1016/0013-4686(82)80035-2

[30] Hassan, H.H., Ibrahim, M.A.M., Abd El Rehim, S.S. and Amin, M.A. (2010) Comparative Studies of the Electrochemical Behavior of Silver Electrode in Chloride, Bromide and Iodide Aqueous Solutions. International Journal of Electrochemical Science, 5, 278-294. http://www.electrochemsci.org/papers/vol5/5020278.pdf

[31] Bard, A.J. and Faulkner, L.L. (2001) Electrochemical Methods: Fundamentals and Applications. 2nd Edition, John Wiley \& Sons, Hoboken, NJ, 210-216. 